\title{
Expressão de caderinas e fator repressor em tumor de pacientes com câncer de mama na presença ou ausência de células malignas em medula óssea
}

\author{
Cadherins and repressor tumor factor \\ expression in breast cancer patients in \\ the presence or absence of malignant \\ cells in bone marrow
}

\author{
Leonardo Gomes da Fonseca ${ }^{1}$, Cíntia Milani ${ }^{2}$, Ana Paula Santana \\ de Abreu', Maria Lúcia Hirata Katayama'2, Maria Mitzi Brentani', \\ Maria Aparecida Azevedo Koike Folgueira ${ }^{4}$
}

\begin{abstract}
Fonseca LG, Milani C, Abreu APS, Katayama MLK, Brentani MM, Folgueira MAAF. Expressão de caderinas e fator repressor em tumor de pacientes com câncer de mama na presença ou ausência de células malignas em medula óssea. Rev Med (São Paulo). 2007 out.-dez.;86(4):212-8.
\end{abstract}

\begin{abstract}
RESUMO: OBJETIVO: Acredita-se que o perfil gênico do tumor é diferente daquele do tecido normal. Além disso, é possível que o tumor adquira características que lhe conferem potencial de gerar metástases em sítios específicos. A expressão tumoral de Caderinas 3 e 11 (envolvidas em adesão e migração celular), e de CBX3 (repressor transcricional) pode estar relacionada a maior agressividade e potencial invasivo em pacientes com câncer de mama (CM). Nosso objetivo é comparar a expressão de Caderina 3, Caderina 11 e CBX3 em tumor e tecido mamário normal adjacente e correlacionar a expressão tumoral destes genes com colonização da medula óssea (MO) por células tumorais. MÉTODOS: Amostras de tumor, tecido normal peritumoral e MO foram obtidas de 30 pacientes com CM estadio clínico I-III. A expressão de Caderina 3 , Caderina 11 e CBX3 foi avaliada por RT-PCR em tempo real. A presença de células malignas em MO foi determinada por detecção da expressão de citoqueratina 19 por Nested-RT-PCR,. RESULTADOS: Dezessete pacientes (56,7\%) apresentaram células malignas em MO. Houve maior expressão de Caderina 3 e Caderina 11, mas não de CBX3 em tumor em relação ao tecido normal. Não encontramos associação entre expressão tumoral de Caderina 3, Caderina 11 e CBX3 e a presença de células malignas em MO. CONCLUSÃO: A hiperexpressão de Caderina 3 e 11 em tumores em relação ao tecido normal sugere que estes transcritos possam estar relacionados à carcinogênese. A expressão tumoral de Caderina 3, Caderina 11 e CBX3 não parece associada com a disseminação para a MO.
\end{abstract}

DESCRITORES: Neoplasias mamárias. Medula óssea. Caderinas. Expressão gênica.

\footnotetext{
1. Acadêmico do 4 ano do Curso de Graduação da Faculdade de Medicina da Universidade de São Paulo.

2. Laboratório de Investigação Médica - LIM 24. Oncologia Experimental - Faculdade de Medicina da Universidade de São Paulo.

3. Professora Livre Docente e Responsável pelo Laboratório de Investigação Médica - LIM 24. Oncologia Experimental Faculdade de Medicina da Universidade de São Paulo.

4. Professora Livre-Docente da Disciplina de Oncologia - Faculdade de Medicina da Universidade de São Paulo. Endereço para correspondência: Leonardo Gomes da Fonseca. Rua Capote Valente, 171, ap.113. São Paulo, SP. CEP: 05409-000.
} 


\section{INTRODUÇÃO}

$\mathrm{O}$ câncer de mama é o segundo tipo de câncer mais freqüente entre as mulheres no mundo e no Brasil, constituindo um problema de saúde pública. O Instituto Nacional do Câncer estimava a ocorrência de 48.930 casos novos de câncer de mama no Brasil em $2006^{1}$.

Acredita-se que o perfil gênico do tumor é distinto daquele do tecido normal ${ }^{2}$. Dentre os genes que podem estar diferencialmente regulados durante a transformação maligna, podemos citar as caderinas, que constituem um grupo de glicoproteínas com função de adesão célula-célula. A redução da expressão de E-Caderina, por exemplo, foi descrita em carcinomas lobulares invasivos de mama, mas em carcinomas ductais esse evento ainda é pouco esclarecido ${ }^{3}$.

A Caderina 3 (ou P-Caderina) é expressa por uma grande variedade de tecidos durante a embriogênese. Na glândula mamária normal, a proteína é expressa apenas nas células mioepiteliais e nas cap cells (células tronco da mama), mas está expressa em carcinomas de mama avançados e com prognóstico sombrio. Esses dados sugerem que a supressão da expressão de Caderina 3 , presente no tecido mamário normal, é perdida durante o processo de carcinogênese $e^{4}$.

A Caderina 11 (ou OB-caderina) é encontrada em osteoblastos, tecidos embrionários e alguns tipos de câncer como o de estômago, rim e mama. Em linhagens de carcinoma mamário, Pishvaian et al. ${ }^{5}$ detectaram maior expressão gênica de Caderina 11 naquelas com maior potencial invasivo ${ }^{7}$. A Caderina 11 pode estar envolvida no reconhecimento célula-matriz, auxiliando a motilidade celular e, conseqüentemente, a invasão de células tumorais através da associação dessas células com células mesenquimais e da matriz, que também expressam essa proteína. Dessa forma, as células malignas podem se associar a osteoblastos, que também expressam Caderina 11, estabelecendo metástases ósseas ${ }^{5}$.

Estudos recentes de análise da expressão gênica sugerem que o tumor já guarda características que lhe conferem potencial metastático desde seu estágio inicial.. Bellahcene et al. ${ }^{12}$ e Lee et al. ${ }^{7}$ descreveram perfis gênico do tumor primário associados à presença de metástases em sítios específicos, como em ossos, linfonodos e pulmão ${ }^{6,7}$. Além disso, Woelfle et al. ${ }^{8}$ encontraram um perfil molecular de tumor primário associado com a presença de micrometástases em medula óssea no qual $90 \%$ dos genes avaliados estavam reprimidos.

A repressão gênica resulta de vários mecanismos que incluem a metilação de histonas e modificação do estado de condensação da cromatina. CBX3 (ou mHP1 gamma) é uma proteína da classe "chromobox" envolvida na modificação da cromatina para um estado de maior condensação, que é repressivo para a expressão gênica. Kirschmann et al. ${ }^{10}$ encontraram maior expressão desse gene em linhagens celulares de câncer de mama mais invasivos ${ }^{9}$. Além disso, dados de nosso grupo mostram maior expressão de CBX3 em amostras de câncer de mama em comparação a tecido mamário normal de pacientes sem câncer invasivo.

Nossa proposta foi determinar se existem variações da expressão dos genes de Caderina 3, Caderina 11 e CBX3 entre tumor de mama e tecido mamário normal adjacente. Outro objetivo foi determinar se a expressão tumoral destes genes está associada à presença de células tumorais na medula óssea.

\section{OBJETIVOS}

- Determinar a expressão de Caderina 11, Caderina 3 e CBX3 em amostras de tecido normal e tumoral de pacientes com câncer de mama.

- Avaliar a presença de células malignas tumorais na medula óssea de pacientes com câncer de mama pela pesquisa da expressão gênica de CK19.

- Avaliar se existe diferença de expressão de Caderina 3, Caderina 11 e CBX3 em tumores de pacientes com presença e ausência de células malignas na medula óssea.

\section{CASUÍSTICA E MÉTODOS}

\section{Casuística}

As pacientes incluídas no projeto foram atendidas no Instituto Brasileiro de Controle do Câncer (IBCC). Todas as pacientes incluídas apresentavam diagnóstico de carcinoma ductal invasivo de mama comprovado por exame histopatológico. A pesquisa foi aprovada pelo comitê de ética da instituição e as pacientes concordaram em participar do trabalho e assinaram o Termo de Consetimento Livre e Esclarecido.

A idade mediana das pacientes foi de 61 anos. Em relação ao estadiamento clínico, 15 (50\%) se apresentaram em estadio II, 9 (30\%) em estádio III e 6 pacientes $(20 \%)$ em estadio I. À análise histopatológica dos linfonodos axilares, 18 (60\%) pacientes apresentaram comprometimento tumoral (Tabela 1). 
Fonseca LG et al. Expressão de caderinas e fator repressor em tumor.

Tabela 1. Características clínicas, patológicas e imunohistoquímicas das pacientes e tumores

\begin{tabular}{l|l}
\hline Características & Média \\
\hline Idade & $62,3 \mathrm{anos}$ \\
Tamanho do tumor (cm) & $2,78 \mathrm{~cm}$ \\
Grau Histológico & $27(90 \%)$ \\
2 & $3(10 \%)$ \\
3 & \\
Comprometimento de linfonodo & $12(40 \%)$ \\
Não & $18(60 \%)$ \\
Sim & $6(20 \%)$ \\
Estadiamento Clínico & $15(50 \%)$ \\
I & $9(30 \%)$ \\
II & $13(43,3 \%)$ \\
III & $17(56,7 \%)$ \\
Receptor de estrógeno & \\
Negativo & $12(40 \%)$ \\
Positivo & $18(60 \%)$ \\
Receptor de progesterona & \\
Negativo & \\
Positivo &
\end{tabular}

\section{Coleta das amostras}

De cada paciente, foram colhidas amostras de tumor primário, de tecido normal peritumoral (a $2 \mathrm{~cm}$ do tumor) e de aspirado de medula óssea durante a cirurgia de ressecção do tumor. As amostras de tecido normal peritumoral e de tumor foram preservadas em nitrogênio líquido e pulverizadas com uso do aparelho Termovac $^{T M}$ (Termolab, EUA). O material puncionado de medula óssea foi processado com reagente Ficoll-Plaque Plus ${ }^{T M}$ (Amersham Biosciences, Inglaterra) e centrifugado (2000 rpm,15 minutos) com a finalidade de se obter separadamente as células mononucleares.

Extração de RNA total e Reação de Transcriptase Reversa para obtenção de DNA complementar

A extração de RNA total das amostras de tecido normal, tumor e medula óssea foi feita com uso do reagente Trizol $\circledR$ (solução monofásica de fenol e isotiocianato de guanidina) (Invitrogen, EUA) seguindo as orientações do fabricante. A partir de $2 \mu \mathrm{g}$ de RNA, realizou-se Transcrição Reversa com kit Super Script III® (Invitrogen, EUA), seguindo orientações do fabricante, para obtenção de DNA complementar (cDNA).

\section{Nested-PCR}

$\mathrm{O}$ cDNA obtido a partir da $\mathrm{MO}$ das pacientes foi amplificado com primers para Citoqueratina 19 (CK19), que é uma molécula do citoesqueleto de células epiteliais e que, portanto, é expressa em células do câncer e não em células que normalmente habitam a medula óssea. Utilizamos $2 \mu \mathrm{l}$ do cDNA , $2 \mu \mathrm{l}$ de tampão 10x (200mM TrisHCl pH 8.4; 500mM KCl), $2 \mu \mathrm{l}$ de dNTPs (200nM), 0,6 4 l de cloreto de magnésio (50 mM) (Invitrogen, EUA), $2 \mu$ l de tampão da Taq

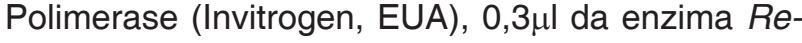
combinant Taq DNA Polymerase $(5 \mathrm{U} / \mu \mathrm{l})$ (Invitrogen, EUA), $10,1 \mu$ l de água deionizada, $1 \mu$ do primer direto, e $1 \mu$ do primer indireto. As condições para a reação foram de $95^{\circ} \mathrm{C}$ por 5 minutos, $94^{\circ} \mathrm{C}$ por 1 minuto, $60^{\circ} \mathrm{C}$ por 1 minuto, $72^{\circ} \mathrm{C}$ por 1 minuto e $72^{\circ} \mathrm{C}$ por 10 minutos. Foram realizados 35 ciclos de amplificação externa de PCR e 30 ciclos na interna. As reações ocorreram em termociclador Gene Amp PCR System 9700 (Applied Biosystem, Estados Unidos).

\section{Real Time- PCR}

Para a reação de $P C R$-Real Time, utilizamos 500ng de DNA; 3 $\mu$ l de Buffer PCR 10x (Invitrogen, EUA); $1,2 \mu \mathrm{l}$ de $\mathrm{MgCl}_{2}$ (Invitrogen, EUA); 2,4 $\mu \mathrm{l}$ de dNTPs; $0,6 \mu$ l de oligonucleotídeo direto e 0,6ul de oligonucleotídeo reverso; $1,5 \mu$ l de dimetil-sulfoxida; $0,45 \mu \mathrm{l}$ de Taq Polymerase (Invitrogen, EUA) e 0,3 $\mu$ l de Sybr Green, este último, ao se ligar a dupla fita de DNA, emite fluorescência a ser captada pelo aparelho termociclador. As condições para a reação foram as seguintes: $95^{\circ} \mathrm{C}$ por 10 minutos; 40 ciclos com $95^{\circ} \mathrm{C}$ por 15 segundos, $60^{\circ} \mathrm{C}$ por 60 segundos e $72^{\circ}$ por 60 segundos; e 45 segundos com variação crescente de temperatura de $72^{\circ} \mathrm{C}$ a $95^{\circ} \mathrm{C}$. As reações de $P C R$ Real Time foram realizadas no aparelho termociclador RotorGene 3000 (Corbett Research, Australia).

\section{Quantificação da expressão gênica - Método $2^{-\Delta \Delta \mathrm{X} \tau}$}

A análise da expressão gênica por meio de PCR em tempo real usado em nosso estudo representa uma quantificação relativa dos genes de interesse (Caderina 3, Caderina 11 e CBX3) com relação à $\beta$-actina, gene constitutivamente expresso, ou seja, que não apresenta variação em sua expressão entre as amostras avaliadas. O método de quantificação $\left(2^{-\Delta \Delta \mathrm{X} \tau}\right)$ requer comparação da expressão dos genes de interesse em grupo controle, que neste estudo foi linhagem celular epitelial mamária HB4A e de carcinoma ductal invasivo MDA-MB 231. 


\section{Análise estatística}

A expressão gênica de Caderina 3, Caderina 11 e CBX3 no tecido normal e tumor é apresentada com valores de média e desvio padrão. A significância da diferença entre grupos (Normal/Tumor e $\mathrm{MO}+/-$ ) foram avaliadas por teste T-Student com a utilização do programa de computador SSPS 11.0.(SPSS, Chicago, IL, EUA) Um valor de $p<0,05$ (bicaudado) foi considerado estatisticamente significativo.

\section{RESULTADOS}

Presença de Células tumorais em medula óssea

Células tumorais isoladas em MO foram detectadas pela expressão gênica positiva de CK19 em $17(56,7 \%)$ pacientes do estudo, mas não em MO de outras 13 pacientes $(43,3 \%)$ (Figura 1$)$.

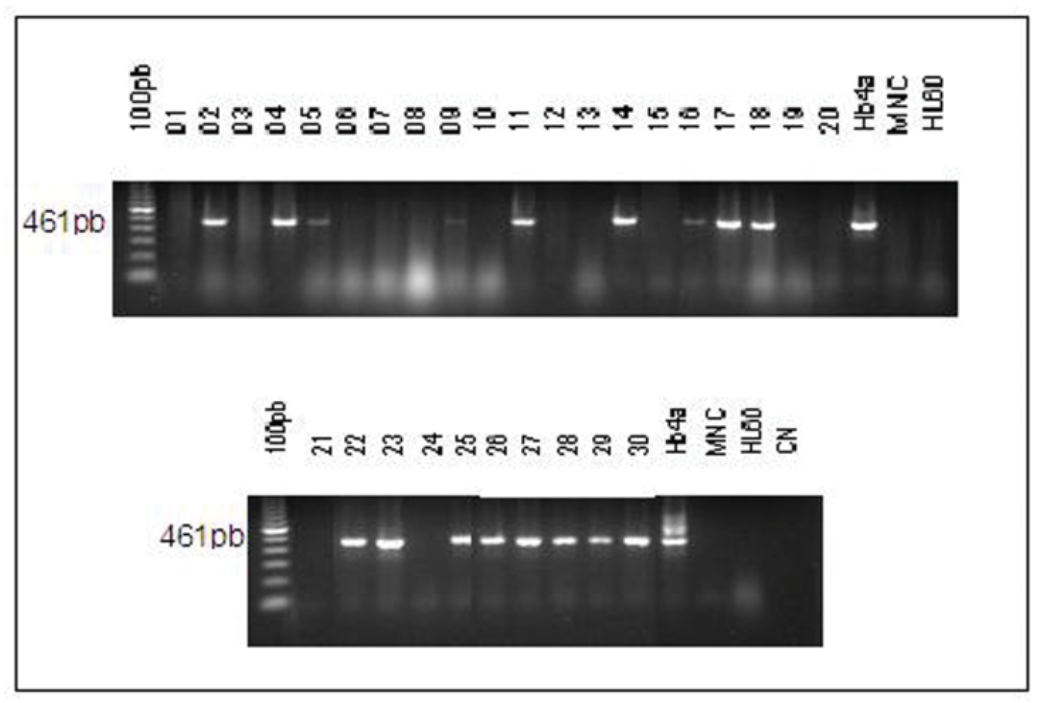

Figura 1. Expressão de CK19 em medula óssea das pacientes com câncer de mama (1 a 30). Hb4a - linhagem epitelial de mama normal, MNC - células mononucleares de sangue periférico, HL60 - linhagem de células de leucemia promielocítica, $\mathrm{CN}$ - controle negativo (reação sem amostra)

Expressão de Caderina 3, Caderina 11 e CBX3 em tumor de mama e tecido normal adjacente

A expressão de Caderina 3 e Caderina 11 na amostra do tumor foi maior em comparação ao tecido normal adjacente. Não detectamos diferença estatística na expressão de CBX3 nos dois grupos (Tabela 2 e Figura 2).

Tabela 2. Expressão gênica de Caderina3, Caderina 11 e CBX3 em tecido normal e tumor. (Teste T de Student)

\begin{tabular}{lccc}
\hline & Média & Desvio Padrão & $\mathrm{P}$ \\
\hline Caderina 3 & & & 0,05 \\
Tecido Normal & 0,38 & 0,59 & \\
Tumor & 1,44 & 2,61 & 0,032 \\
Caderina 11 & & & \\
Tecido Normal & 281,34 & 375,26 & \\
Tumor & 515,96 & 557,94 & 0,639 \\
CBX3 & & & \\
Tecido Normal & 15,99 & 25,45 & \\
Tumor & 17,98 & 28,41 & \\
\hline
\end{tabular}




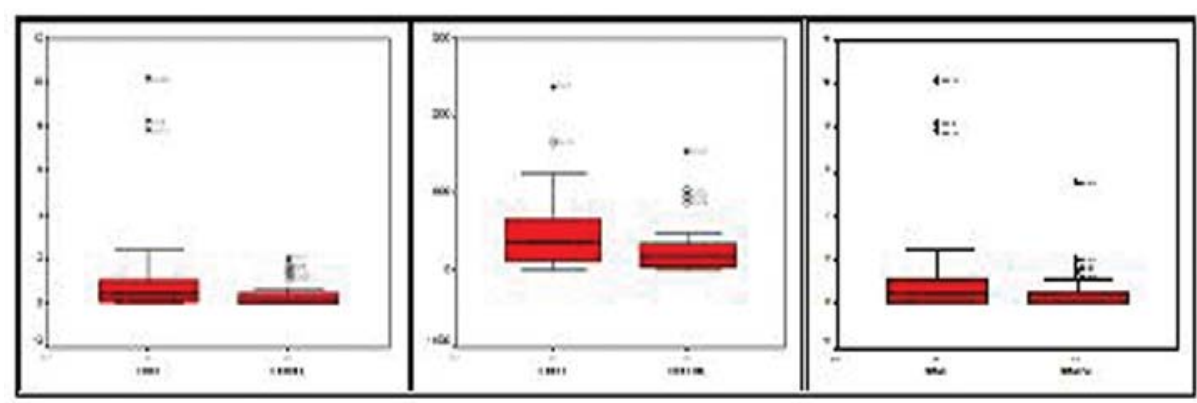

Figura 2. Boxplot mostrando a distribuição dos valores da expressão gênica de Caderina 3 (à esquerda), Caderina 11 (centro) e CBX3 (à direita) em tecido normal e tumor. Todos os valores estão distribuídos entre as barras (os quartis 25 , 50 e 75 aparecem na caixa vermelha), exceto os valores extremos, representados com os sinais ( $\left.{ }^{\circ}\right)$ quando maiores que 1,5 vezes e $\left(^{*}\right)$ quando maiores que 3 vezes o quartil 75 .

Expressão tumoral de Caderina 3, Caderina 11 e CBX3 e presença de células tumorais em MO

Não encontramos diferença na expressão tumoral de Caderina 3, Caderina 11 e CBX3 em pacientes com MO invadida por células tumorais em relação àqueles sem invasão de $\mathrm{MO}$ (Tabela 3 e Figura 3).

Tabela 3. Expressão gênica tumoral de Caderina 3, Caderina 11 e CBX3 em pacientes na presença e ausência de células tumorais em medula óssea (Teste T de Student)

\begin{tabular}{llll}
\hline & Média & Desvio Padrão & $\mathrm{P}$ \\
\hline Caderina 3 & & & 0,266 \\
MO - & 0,925 & 1,891 & \\
MO + & 2,076 & 3,217 & 0,243 \\
Caderina 11 & 387,31 & 442,52 & \\
MO - & 656,15 & 674,83 & 0,138 \\
MO+ & & 11,184 & \\
CBX3 & 10,101 & 40,494 & \\
MO - & 29,14 & & \\
MO & &
\end{tabular}

MO+: presença de células tumorais em medula óssea

MO-: ausência de células tumorais em medula óssea

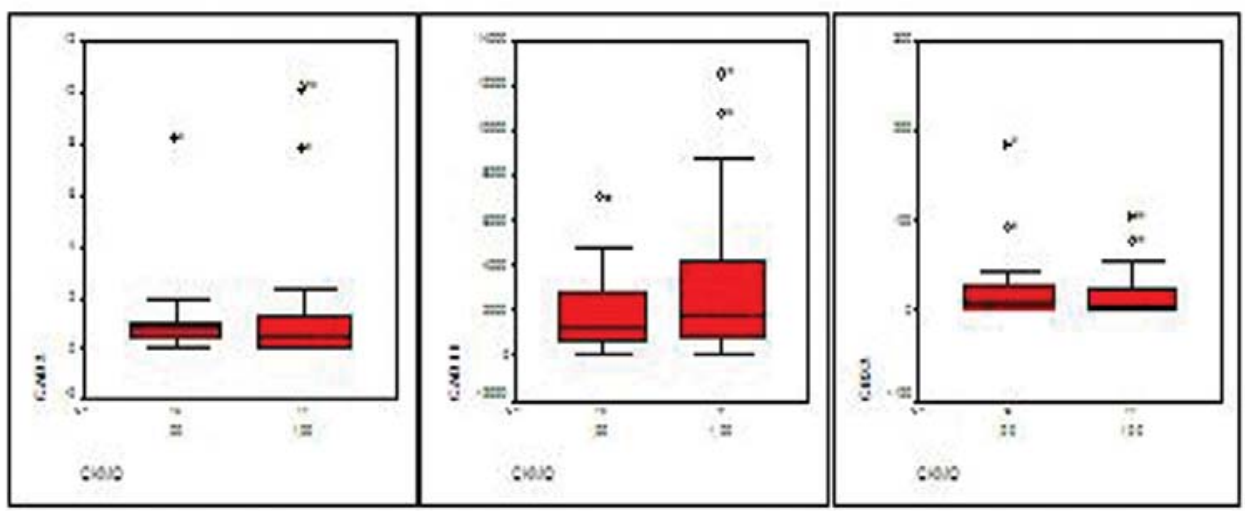

Figura 3. Boxplot mostrando a distribuição dos valores da expressão tumoral de Caderina 3 (à esquerda), Caderina 11 (centro) e CBX3 (à direita) nos grupos MO positiva (1) e negativa (0) para CK19. Todos os valores estão distribuídos entre as barras (os quartis 25, 50 e 75 aparecem na caixa vermelha), exceto os valores extremos, representados com os sinais $\left({ }^{\circ}\right)$ quando maiores que 1,5 vezes $\left(^{*}\right)$ quando maiores que 3 vezes o quartil 75 


\section{DISCUSSÃO}

A identificação de genes diferencialmente expressos no câncer de mama tem auxiliado o entendimento dos mecanismos da doença e a escolha de condutas terapêuticas individualizadas, o que pode proporcionar abordagem mais adequada e eficaz das pacientes com câncer de mama.

Observamos em nosso trabalho que a expressão de Caderina 3 e Caderina 11, mas não de CBX3, é maior no tumor de mama em relação ao tecido normal adjacente. Por outro lado, não existe expressão diferencial destes genes em amostras de tumor de pacientes de acordo com presença ou ausência de células malignas em medula óssea.

De acordo com nossos dados, Paredes et al. ${ }^{11}$ observaram ausência de expressão de Caderina 3 em células epiteliais mamárias normais e identificaram a metilação em sítios promotores como mecanismo de repressão deste gene. Por outro lado, em células de câncer de mama encontrou-se hipometilação e expressão de Caderina 3. Dessa forma, é possível que a metilação inviabilize a ligação de fatores transcricionais na região promotora, impedindo a expressão da proteína em tecido mamário normal. Durante o processo de carcinogênese, entretanto, a hipometilação destes sítios determina a expressão de Caderina 3 em células tumorais ${ }^{11}$.

A Caderina 11, ou OB-Caderina, é uma proteína transmembrana encontrada em osteoblastos, tecidos embrionários e alguns tipos de câncer como de estômago, rim e mama ${ }^{5}$. Além disso, a expressão aumentada de Caderina 11 ocorre em linhagens de carcinoma de mama invasivo com capacidade de gerar metástase óssea em relação a linhagem epitelial mamária normal, porém pouco se sabe sobre seus mecanismos regulatórios ${ }^{12}$.

Existem evidências que a Caderina 11 possa estar envolvida no reconhecimento célula-matriz, facilitando a motilidade celular e a associação de células tumorais com osteoblastos no processo de metastatização óssea. Logo, é possível que, durante o processo de transformação maligna, ocorra expressão de genes, como a Caderina 11, que irão determinar a ocorrência de metástases ósseas no futuro ${ }^{13}$. Entretanto, somente a observação da evolução clínica a longo prazo nas pacientes de nosso estudo, para detectar quais delas desenvolveriam metástases ósseas, nos daria tal informação.

Diversos estudos apontam que a repressão gênica é um mecanismo importante na progressão tumoral. Entretanto, a expressão de CBX3 em tecido normal adjacente e tumor foi semelhante em nosso estudo, de modo que é possível que no tecido peritumoral já ocorram alterações précancerosas, como a expressão de CBX3.

Vários estudos de análise da expressão gênica sugerem que o tumor já guarda características que lhe conferem potencial metastático desde seu estágio inicial. Desse modo, Bellahcene et al. (2006) descreveram um perfil gênico em tumor primário que está associado a presença de metástases ósseas. Nesse perfil, houve maior expressão de Caderina 11 e menor expressão de E-Caderina em tumores de pacientes com metástases óssea em relação às pacientes sem metástases ósseas ${ }^{6}$. Lee et al. ${ }^{7}$ relataram um perfil gênico relacionado à ocorrência de metástase linfonodal, enquanto Minn et al. ${ }^{14}$ identificaram um perfil gênico que medeia a metástase pulmonar em câncer de mama.

Woelfle et al. ${ }^{8}$ encontraram um perfil molecular de tumor primário associado com a presença de micrometástases em medula óssea, no qual $90 \%$ dos genes avaliados estavam reprimidos. Em nosso estudo, detectamos micrometástases em 56,7\% das pacientes porém não foi possível identificar um perfil gênico relacionado a presença de células tumorais em medula óssea, visto que os genes avaliados não mostraram diferença de expressão em pacientes na presença ou ausência de células tumorais na medula óssea. Portanto, é possível que outros repressores transcricionais, como CBX1, CBX5 e genes relacionados à metilação de sítios de DNA, estejam associados a esse perfil gênico. Da mesma forma, as Caderinas 3 e 11 não parecem exercer papel no processo de invasão e colonização do microambiente medular.

É importante ressaltar que marcadores moleculares do tumor podem ser alvo de terapia específica. Além disso, o estudo do perfil genético dos tumores pode permitir a identificação de vias de sinalização ativadas ou reprimidas e potenciais alvos de modulação no tratamento desta doença. Dessa forma, novas pesquisas poderão implicar melhora no tratamento das pacientes com câncer de mama. 
Fonseca LG et al. Expressão de caderinas e fator repressor em tumor.

Fonseca LG, Milani C, Abreu APS, Katayama MLK, Brentani MM, Folgueira MAAF. Cadherins and repressor tumor factor expression in breast cancer patients in the presence or absence of malignant cells in bone marrow. Rev Med (São Paulo). 2007 out.-dez.;86(4):212-8.

ABSTRACT: PURPOSE: Gene profile is believed to be different in tumor and normal tissue. Besides, it is possible that tumor acquires characteristics that provide ability to develop metastasis in specific sites. Tumoral expression of Cadherins 3 and 11 (involved with adhesion and cellular migration) and $\mathrm{CBX} 3$ (transcriptional repressor) may be related to aggressiveness and lower survival in breast cancer (BC) patients. Our purpose is to compare tumoral and normal mammary tissue expression of Cadherin 3, Cadherin 11 and CBX3 and to correlate tumoral expression of these genes with bone marrow (BM) colonization by tumoral cells. METHODS: Samples of tumor, normal tissue and BM were obtained from $30 \mathrm{BC}$ patients stage I-III. Expression of Cadherin 3, Cadherin 11 and CBX3 were analysed by RT- PCR-Real Time. Malignant cells in BM were determined by CK19 expression in Nested-PCR. RESULTS: Seventeen patients $(56,7 \%)$ had malignat cells in BM. There was hiperexpression of Cadherin 3 and Cadherin 11 , but not of $\mathrm{CBX} 3$, in tumor in relation to normal tissue. We did not find association between tumor expression of Cadherin3, Cadherin 11 and $\mathrm{CBx} 3$ and presence of tumor cells in BM. CONCLUSIONS: Hiperexpression of Cadherin 3 and Cadherin 11 in tumor in relation to normal tissue suggests that these genes can be associated to carcinogenesis. Tumor expression of Cadherin 3, Cadherin 11 and CBX3 were not associated to BM dissemination.

KEY WORDS: Breast neoplasms. Bone marrow. Cadherins. Gene expression.

\section{REFERÊNCIAS}

1 Brasil. Ministério da Saúde. Instituto Nacional de Controle do Câncer. Disponível em: http://www.inca. org.br

2 Perou CM, Sorlie T, Eisen MB, van de Rijn M, Jeffrey SS, Rees CA, et al. Molecular portraits of human breast tumours. Nature. 2000;406(6797):747.

3 Rasbridge, SA, Gillet, CE, Sampson, SA, Walsh, FS, Millis, RR. Epithelial (E-) and placental (P-) cadherin cell adhesion molecule expression in breast carcinoma. J Pathol.1993;169(2):245-50.

4 Palacios J., Benito N, Pizarro A, Suarez A, Espada J, Cano A, et al. Anomalous expression of P-cadherin in breast carcinoma. Correlation with E-cadherin expression and pathological features. Am J Pathol. 1996;146(3):605-12.

5 Pishvaian MJ, Feltes CM, Thompson P, Byers SW. Cadherin-11 is expressed in invasive breast cancer cell lines. Cancer Res. 2002;59:947-52.

6 Bellahcene A, Bachelier R, Detry C, Lidereau R Clezardin $\mathrm{P}$, Castronovo V. Transcriptome analysis reveals na osteoblast like phenotype for humanosteotropic breast câncer cells. Breast cancer Res Treat. 2006;20:292-301.

7 Lee KW, Kim JH, Park JH, Kim HP, Song SH, Jung $\mathrm{KH}$, Bang YJ. Antitumor activity of SK-7041, a novel histone deacetylase inhibitor, in human lung and breast cancer cells. Anticancer Res. 2006;26(5A):3429-38.
8 Woelfle, U, Closs, J, Sauter, G, Pantel, K. Molecular signature associated with bone marrow micrometastasis in human breast cancer. Cancer Res. 2003;5679-84.

9 Kirshmann, DA, Lininger, RA, Odero, VA. Down regulation of HP1 expression is associated with metastatic phenotype in breast cancer. Cancer Res. 2000;60:3359-63.

10 Folgueira MAAK, Carraro DM, Silva RLA, Zaiats AC, Soares FA, Oliveira CT, et al. Gene expression profile associated to advanced breast cancer. In: ThirtyNinth Annual Meeting of American Society of Clinical Oncology, 2003.

11 Paredes, J, Stove, C, Milanezi, F, Marck, VV. $\mathrm{P}$-Cadherin is up-regulated by the antiestrogen $\mathrm{ICI} 182$, 780 and promotes invasion of human breast cancer cells. Cancer Res. 2004;64:8309-17.

12 Bellahcene A, Castronovo V: Expression of bone matrix proteins in human breast cancer: potential roles in microcalcification formation and in the genesis of bone metastases. Bull Cancer. 1997;84:17-24.

13 Feltes CM, Knudo A, Blashku O, Byers W. An alternatively spliced Cadherin 11 enhances breast cancer cell invasion. Cancer Res. 1999;62:6668-97.

14 Minn AJ, Gupta GP, Siegel PM, Bos PD, Shu W, Giri $\mathrm{DD}$, et al. Genes that mediate breast cancer metastasis to lung. Nature. 2005;28;436(7050):518-24. 